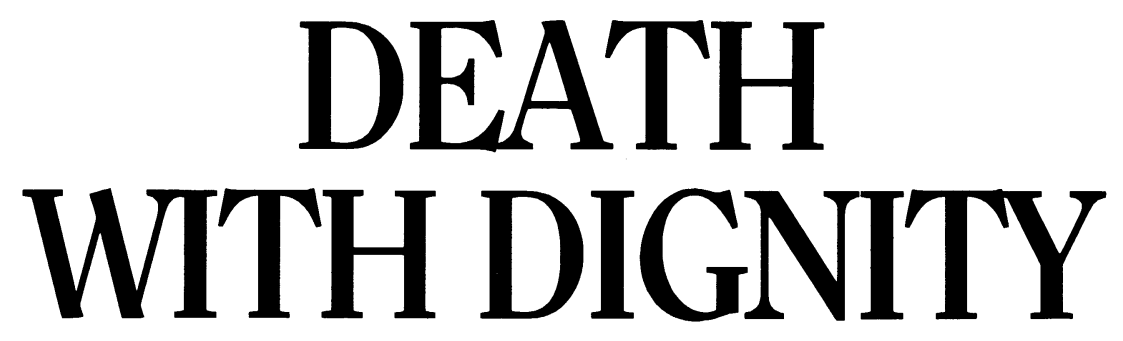


Dedicated to the illustrator

Clare Passmore (1964-1989) 


\title{
DEATH WITH DIGNITY
}

\author{
by \\ Jennifer Green \\ Consultant in Public Health Medicine, \\ Pontefract Health Authority \\ Edited by Joanna Trevelyan, \\ Features Editor, Nursing Times \\ Designed by Susie Lanni
}

NT

A NURSING TIMES PUBLICATION 


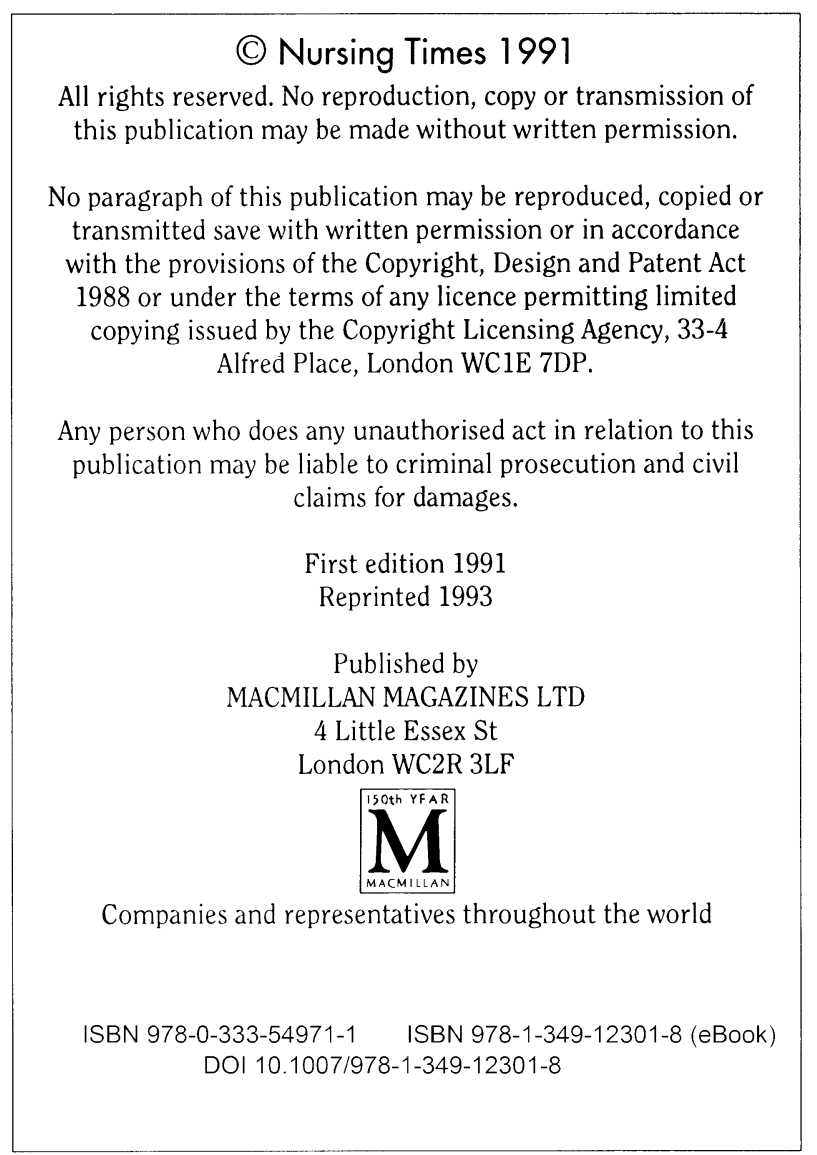




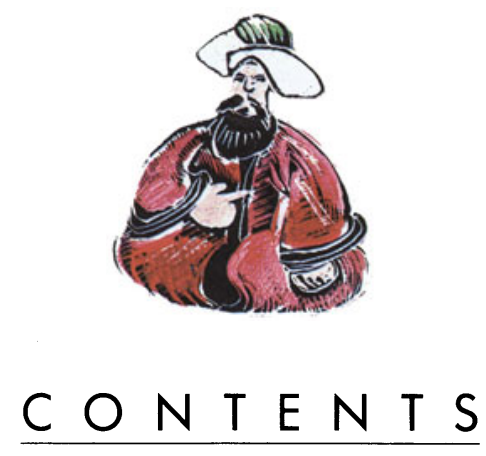

\section{INTRODUCTION 1 \\ $\underset{2}{\text { ISLAM }}$}

HINDUISM
$\mathbf{4}$

SIKHISM

6

JUDAISM

8

BUDDHISM

10

BAHA'I FAITH

12

FUNERALS ABROAD

14

RESOURCE LIST

15

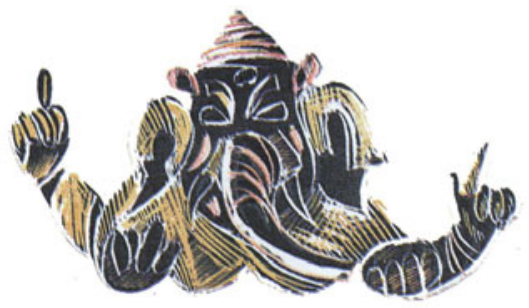

